\title{
ÉTICA, CIÊNCIA, UNIVERSIDADE... entrevista com Roberto Romano
}

PALAVRAS-CHAVE: Ética; universidade; moral. KEY WORDS: Ethics; university; moral.

PALABRAS-CLAVE: Etica; universidad; moral.

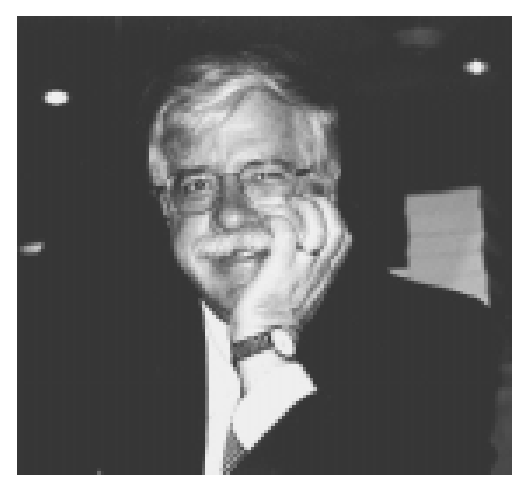

Esta entrevista aconteceu numa terça-feira do mês de novembro.

O cenário: uma tarde pós-chuva, iluminada pelo sol que tomava conta do céu paulistano... uma casa cercada por um jardim com bromélias, trepadeiras, gerânios... cheiro de jasmim e canto de passarinhos invadindo o escritório... café e biscoitos caseiros...

O tema: ética, moral, ciência, universidade...

O entrevistado: Roberto Romano.

Filósofo, com doutorado na École des Hautes Études en Sciences Sociales, Paris, Roberto Romano é professor adjunto da Faculdade de Educação da Universidade Estadual de Campinas - Unicamp, onde exerce o cargo de vicediretor. Com inúmeras publicações na área de Ciências Sociais, é figura incontestável no cenário intelectual brasileiro, por expressar posicionamentos críticos sobre temas extremamente complexos e de grande relevância atual.

A seriedade necessária a quem é autoridade no assunto, aliada à maneira informal com que transcorreu nossa conversa, resultou num texto ao mesmo tempo profundo e de uma leitura intensamente prazeirosa. O público-alvo: você, leitor.

\footnotetext{
${ }^{1}$ Entrevista realizada pela professora Maria Lúcia Toralles-Pereira (Instituto de Biociências de Botucatu, Universidade Estadual Paulista/ UNESP), com colaboração de Adriana Ribeiro (assistente editorial da Revista Interface, Fundação Uni). <intface@fmb.unesp.br>
} 


\section{sobre Ética e Moral}

Procuro sempre, no interior da vida intelectual brasileira, discutir criticamente o conceito imperante de ética porque vejo nele um grande perigo. No Brasil de hoje, quando se fala no assunto, o termo recebe quase imediatamente a conotação de algo positivo, desejável e bom. A ética definiria as regras de ação recomendáveis para o coletivo e os indivíduos. Semelhante identificação do ético com o bom é problemática. O conceito de ética é mais abrangente do que as noções de bem e de mal, pois significa o conjunto de hábitos introduzidos e reiterados num determinado tempo e sociedade, tornando-se quase automáticos nas consciências humanas, como se fossem uma segunda natureza. Qualquer ato nosso, reflexivo ou ativo, pode ter conotação boa ou má. Muitos hábitos coletivos, introduzidos no transcurso da história, sobretudo no Ocidente, na Europa e Américas, são nocivos à vida espiritual. Há o campo enorme de representações coletivas que a Filosofia do século XVII ou XVIII definia como "preconceitos". Que um valor seja aceito por sociedades nacionais ou transnacionais como inquestionável é um ponto. Que ele seja inquestionável é algo muito diferente. Por exemplo, temos o anti-semitismo. Trata-se de uma forma de comportamento presa ao conjunto de valores surgidos na Idade Média, a partir de equívocos doutrinários, históricos e religiosos. Ao longo da Idade Média e no início do Estado Moderno, ele foi ampliado por problemas de ordem econômica e política, sendo reiterado por juízos equivocados, emitidos por grandes homens e líderes religiosos, como é o caso de Lutero. $\mathrm{Na}$ História Moderna ele foi repetido pelos seguidores de Lutero e também do catolicismo. No século XIX o anti-semitismo uniu-se às doutrinas supostamente científicas, de cunho racista. Tais doutrinas foram espalhadas por meio da imprensa, das cátedras universitárias, dos livros, e tornaram-se uma forma "espontânea" de pensar entre largas camadas da população. Na Alemanha, quando surgiu o nazismo, ele já encontrou um solo fértil de atitudes diante do judeu, do árabe etc... O nazismo vem coroar um costume plenamente ético, mas hediondo e imoral, já que sapa a consciência moral que exige a unidade do ser humano: judeus, árabes ou negros, todos integram o ser humano. O ético, assim entendido, tem um atrativo muito grande, porque nele se descreve o "concreto", a vida do povo. O moral é mais abstrato, porque apela para a consciência invisível. Mas o moral é importante para verificarmos a veracidade, a bondade do ético. Este último é necessariamente coletivo: não existe ética individual. Já o moral apresenta-se coletivamente mas tem sua vigência na individualidade. O juízo moral exige que se suspenda temporariamente o juízo ético, pois ele é mais exigente que o ético. Quem defende uma linha puramente ética da cultura, critica o chamado "moralismo"- o moralismo abstrato - porque ele seria uma afirmação de valores que não se corporifica imediatamente, enquanto o contrário ocorre com o ético. O ético, pois, é muito mais atraente. A "opinião pública" quase sempre é ética (o que não quer dizer que é exata!).

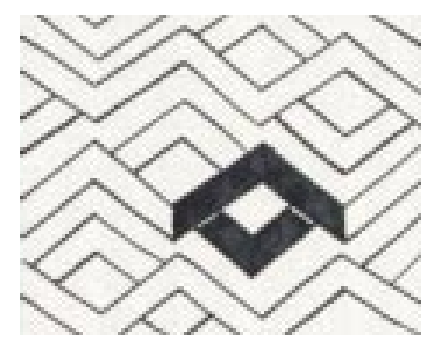


Há casos horrendos de costumes éticos, como, por exemplo, no caso brasileiro, a falta de respeito pelas leis de trânsito. Esta atitude coletiva entre nós pode ser vista, pelos estudiosos do fato ético, como um costume sancionado. Mas trata-se de algo plenamente imoral, porque nele tem-se em mente a prioridade do material sobre o espiritual. Se alguém possui condições econômicas para adquirir um veículo importado da marca Audi, consegue o direito de matar. Na consciência dos atores sociais existe esse direito, o que é profundamente imoral e anti-ético, no sentido correto da palavra. Não há dono de carro Audi (a não ser que ele seja um sujeito moral extremamente elevado), que não acredite: sua posse de um Audi goza do privilégio de andar a 170 quilômetros por hora numa estrada pública. A própria propaganda da Audi incentiva isso: "quando você enxergar esse logotipo, passe para a direita". Atribui-se aos donos de veículos o estatuto de semideuses, acima do bem e do mal. Por tudo isso eu me preocupo muito com a veiculação sem prudência da "ética" como se ela fosse um corretivo para a sociedade brasileira. Acho que a nossa vida social, inclusive a universidade e a pesquisa brasileiras, estão profundamente marcadas por traços éticos indesejáveis.

Um outro exemplo ... Tomemos as relações de favor. Elas imperam nas políticas municipais e nacionais, na vida aquisitiva e mesmo na captação de recursos para a pesquisa. No Brasil o costume é esse: você tem um projeto objetivamente bom - do ponto de vista científico, acadêmico, metodológico $e$, no entanto, sempre precisa ter alguém que dê a "mãozinha", interceda, esteja presente nos Conselhos, para que o seu projeto saia do anonimato. Mas o preceito democrático é justamente o anonimato, o valor da coisa $e$ não da pessoa. As fórmulas conhecidas, como o "sabe com quem está falando" e o QI (quem indica?), infelizmente modelam boa parte das relações científicas, acadêmicas. Esse ponto ético da cultura brasileira merece ser reformulado, para que não exista mais a guerra de todos contra todos, a formação de pequenos grupos de influências para troca de favores... Só quem desconhece a realidade social brasileira $e$ a realidade social das universidades e das próprias Fundações de Pesquisa ousa dizer que nelas não existem esses nexos de influência pessoal.

Outro ponto gravíssimo do ponto de vista ético: temos Fundações que operam segundo o pressuposto do anonimato do parecerista. Mas este último raramente assume todas as dimensões da ética e da moral. Muitas vezes - e cada vez mais - o parecerista utiliza o anonimato para combater inimigos ou adversários do ponto de vista metodológico, ideológico e, até mesmo, doutrinário. Muitos não têm dúvidas em cortar recursos para a pesquisa dos que pensam de forma diferente. Esta é uma fonte de tensão enorme na comunidade acadêmica. E dizem tratar-se de uma prática com preceitos éticos. Para mim, trata-se de algo profundamente imoral. Defendo, como uma parte da democratização da pesquisa brasileira, o fim do anonimato do parecerista. Esta é uma atitude de responsabilidade social, porque numa Fundação de direito público, com recursos públicos, não há direito ao anonimato. A alocação - ou não - de dinheiro deve ser examinada pelo público, porque é ele que paga. O anonimato é profundamente antiético, é imoral e viceja sob a capa da ética. 


\section{sobre os códigos de ética,}

\section{especialmente no campo da Saúde...}

Em primeiro lugar, precisamos verificar como um código de ética foi enunciado. Se o foi por uma instituição que tem em vista apenas os interesses de política imediata ele é, logo de início, inválido, porque traduz o desejo de uma parte - embora hegemônica - a definir o campo inteiro. Penso que um código de ética deve resultar de debates que incluam o que há de mais avançado e de mais responsável em cada setor científico. Não basta que a pessoa tenha valores. É preciso que esses valores sofram a prova do conhecimento, caso contrário estaremos reiterando o velho veto das instituições religiosas à própria pesquisa científica ou artística. Gosto de lembrar um exemplo clássico na história de nossos costumes. Quando saiu o filme "O padre e a moça", o arcebispo de São Paulo proibiu os católicos de assistirem ao filme. Perguntaram-lhe: "o senhor assistiu?". E ele disse: "como posso ver algo que eu proibi para os outros?". Na Ciência isto não é permitido. Se for feito um código de ética desprovido de conhecimentos científicos, ele já surge de modo anacrônico e contraproducente. Além disso, no código de ética é necessário levar em conta o traço mais antigo da sabedoria humana: a prudência. E prudência não é sempre medo. Nela são pesados todos os elementos em jogo. Nessa medida, um código de ética só pode ser o resultado temporário de um diálogo da comunidade inteira (a comunidade dos médicos, dos psiquiatras, dos matemáticos etc...) em discussão tensa e conflituosa com a sociedade envolvente. Veja que uma série de procedimentos podem ser perfeitamente lícitos e justificáveis para um conjunto de profissionais e, ao mesmo tempo, constituírem uma agressão permanente à sociedade. Muitas vezes a comunidade médica aceita ou absolve procedimentos que são verdadeiros escândalos para o comum dos mortais. Sempre se diz que há uma espécie de corporativismo nas comunidades científicas. No caso dos erros médicos, existem alguns que clamam aos céus, que são um flagrante desrespeito e que exigem ação da Justiça, do Estado. Diante deles, a comunidade médica faz vistas grossas ou absolve erros. Quando se esquecem bandagens dentro do estômago de alguém, isso é gravíssimo. E por que é grave? Porque faltou prudência e perícia por parte dos operadores: faltou conhecimento científico. Aí entramos numa série de outros debates, como a proliferação das Faculdades de Medicina. Formar médicos quase como se faz pão, sem rigor, é um fator genocida que agride a integridade ética da sociedade.

\section{sobre os limites da vida e discussão ética}

Na verdade, os limites da vida e da morte são enfrentados pela humanidade desde seu primeiro vagido no interior da natureza. A partir do momento em que houve certa quebra no interior da natureza e surgiu um animal capaz de pensamento e reflexão surgiram os problemas da ética. Todo e qualquer 
ato técnico humano exige prudência. Por mais sofisticada que seja uma técnica ou um conjunto de saberes, a pergunta sempre é: tais conhecimentos, método ou procedimentos servem para ampliar a vida de um maior número possível de pessoas ou não? Isso é básico. Os cientistas que não conseguirem responder essa questão brincam com a vida humana. $\mathrm{Se}$, ao considerarmos os nexos do indivíduo humano e da natureza que o envolve, aquele conhecimento, técnica, procedimento, serve para ampliar o tempo de vida individual e coletiva, então é inquestionável que eles são eticamente recomendáveis. Agora, se isto não tem uma resposta positiva, deve-se colocar em questão. Não para rejeitar (você não vai recusar procedimentos porque não podem responder positivamente a essa pergunta), mas deve-se questionar sempre. Caso contrário, estaremos reiterando procedimentos como os dos médicos nazistas, que achavam muito interessante fazer certas pesquisas, só que isso não colaborava para o aumento da vida humana. Pelo contrário.

\section{sobre universidade}

Não existem universidades e sociedades ideais. Nós temos a sociedade e a universidade brasileiras, com seus valores e contra-valores produzidos histórica e socialmente. No caso da nossa universidade, creio que ela tem muitos valores. Se pensarmos que a comunidade acadêmica (sobretudo a que vai de Belo Horizonte a Porto Alegre, passando por Rio de Janeiro e São Paulo, incluindo centros de excelência em todo o Brasil) tem padrão de conhecimento e de produção técnica equivalente a muitos países europeus (como é o caso da Itália e da Áustria), vemos o potencial enorme, produzido por uma comunidade científica que merece respeito e deve ser ampliada. Mas se pensarmos que essa comunidade vive num país de 160 milhões de pessoas que não têm acesso à vida, à educação, ao espírito, à ciência... vemos um problema grave e pensamos que algo precisa ser modificado. Esse tesouro acumulado deve ser comunicado. E aí eu vejo um problema muito sério de ordem social e política. A universidade pública brasileira, a mais importante do país do ponto de vista científico, tecnológico ou da pesquisa, convive com um problema gravíssimo: ela é refém da classe média, não tem abertura para as grandes camadas da população pobre do país. Embora a classe média mereça respeito, porque ela paga impostos também, a política da universidade é ligada ao sucesso grupal $e$ individual de seus integrantes. Ela se preocupa muito em como vai fazer o estudante entrar no mercado de trabalho quando sair da universidade, mas os grandes temas sociais, por enquanto, continuam passando ao largo das decisões coletivas. Não digo que na universidade não tenhamos grupos de professores $e$ pesquisadores com interesse na expansão social do conhecimento, mas infelizmente nosso grande alvo coletivo, enquanto universidade, ainda é o sucesso dos nossos alunos no mundo do trabalho.

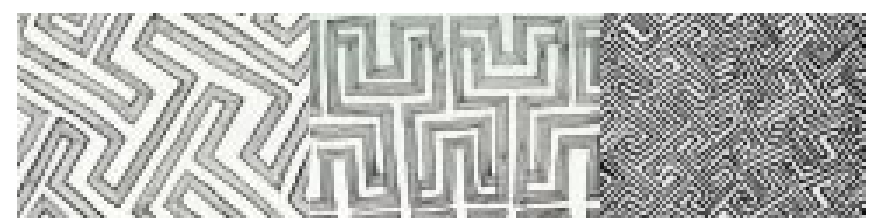


Isso faz com que esqueçamos que somos mantidos pelo imposto do cidadão comum e que não temos compromisso exclusivo com os egressos da classe média. Este ponto, eu não sei como a universidade pública resolverá. $\mathrm{Na}$ política dos vestibulares, no trabalho com o ensino fundamental e médio, com programas sociais de expansão da Ciência e Tecnologia... que tipo de envolvimento devemos ter com isso? A nossa Extensão, por exemplo: antigamente era quase que só benevolência e as Pró-Reitorias de Extensão eram as menos privilegiadas na universidade. Hoje elas são as mais procuradas. Mas quando vamos investigar o conteúdo dessa extensão, notamos que se trata de convênios, os quais permitem aos professores auferirem um pouco mais de recursos - às vezes para sua própria pesquisa $e$ não para seu salário, mas, mesmo assim, sem passar pela extensão social do conhecimento, mantendo as mesmas relações assimétricas: uma elite e uma massa discriminada. Com isso, não saímos do patamar do começo do século $X X$. Entramos no século XXI em que as sociedades sem conhecimento coletivo em Ciência e Tecnologia estão fadadas a desaparecer. Esse é um problema de responsabilidade enorme da universidade.

\section{sobre formacão na área da Saúde}

É preciso não ser maniqueísta. Temos iniciativas de trabalho, até do ponto de vista do Estado, do Governo - o SUS, por exemplo - que merecem ser pensadas como um valor, e não combatidas. No entanto, ainda convivemos com uma grande insegurança na área da Saúde. Voltando à classe média, ela é refém de grupos de saúde. Nos três ramos fundamentais da política pública, o da segurança física, da segurança de saúde e de instrução, o Estado Brasileiro ainda não disse a que veio. Ele aceita uma Saúde Pública que não é estatal nem privada. Se fosse privada, num país um pouco mais rigoroso do ponto de vista do controle do Estado, ela não teria a liberdade de lucro que todos nós constatamos. Temos problemas gravíssimos, mas o principal é o fato de que não somos ainda um Estado. A nossa instituição estatal é permeada por interesses grupais. Entre nós o Estado ainda não tem vigência plena. Veja, o Estado tem três monopólios fundamentais, sem os quais não é Estado: o monopólio da força física - só ele pode prender, fazer a guerra... mas no Brasil vemos grupos privados exercendo a violência física; a norma jurídica e, desse ponto de vista a lei tem que ser universal, o que é quase uma piada no Brasil; e a taxação de excedente econômico, que pressupõe que o Estado cobre impostos da atividade econômica - ora, quando olhamos os dados da Receita Federal vemos que cinqüenta por cento dos empresários não pagam seus impostos. Logo, o Estado não se exerce em plenitude entre nós, o que leva à carência de recursos econômicos para as políticas públicas, à falta de efetividade das leis que garantem essas políticas públicas, e à perda do controle dos corpos pela autoridade pública, fazendo com que a sociedade regrida ao nível da selva. O número de chacinas que testemunhamos no cotidiano mostra que não existe autoridade pública, ou melhor, que a autoridade pública se rebaixou ao nível do particular. Esse é 
um problema não apenas de ordem doutrinária, mas de existência. Temos garantia coletiva de que a sociedade brasileira vai sobreviver por mais cem anos? Eu não teria uma resposta positiva para essa questão. E não se trata de pessimismo, mas de verificar os dados. Voltando ao trânsito. As estatísticas brasileiras sobre o assunto são mais catastróficas do que muitas guerras. A ONU se recusa a aceitar nossos dados de trânsito como acidentes, ela considera assassinatos. Temos milhares e milhares de mortes nas ruas $e$ ou estradas por desobediência à lei, isto é, falta de obediência ao monopólio do Estado. Isso é um ponto. Outro: quantas mulheres morrem nas mãos de curiosos por praticarem o aborto sem assistência médica legal? São milhares. Se houvesse uma lei definitiva, vamos supor, uma lei de cunho integrista católico... mas hoje as mulheres não sabem se podem fazer aborto ou não. $O$ aborto é crime e não é crime. É crime do ponto de vista oficial, mas não é crime quando se trata de resolver um problema e, portanto, o Estado se torna irresponsável. E não se trata de pessimismo, mas de uma percepção real do que está acontecendo: milhares de mulheres, de jovens que morrem numa lógica ambígua, que vai da existência e da não existência do Estado entre nós.

\section{sobre o conflito entre as universidades federais e o Ministério}

Na história do Estado brasileiro há uma tradição de hegemonia do Poder Executivo em todas as instituições. No caso das universidades não foi diferente: 99\% das universidades Federais, Estaduais e Municipais do país surgiram por iniciativa do Poder Público Executivo. São presidentes, governadores, ministros de Estado, prefeitos... que instauram essas universidades as quais já nascem sob a proteção (muitas vezes abafante) do Poder Executivo, afastadas do Legislativo, do Judiciário e da sociedade. Então, o diálogo permanente das universidades, ao longo do século $\mathrm{XX}$, foi com o Executivo. Este, por sua vez, quando instaura essas universidades federais, e mesmo as estaduais, as instaura tendo em vista seu próprio diálogo com as oligarquias dominantes nas regiões, porque o poder público federal é uma abstração para as regiões. Ninguém vive no Brasil, todo mundo vive na Bahia, no Maranhão, em Porto Alegre, ou seja, no município, na região. Entre o poder público e as universidades devemos levar em conta as oligarquias. E boa parte das políticas encaminhadas nas universidades federais, até em termos de pessoal, passa pelas oligarquias. E nós estamos enfrentando um fenômeno muito interessante, que o professor Francisco de Oliveira descreve muito bem, que é o do fim das oligarquias enquanto mediadoras dos recursos materiais da sociedade brasileira. Até hoje, as oligarquias foram sempre filtros que serviram para captar recursos federais e distribuí-los pelas regiões, enriquecendo, evidentemente, seus donos. Com a globalização da economia e a perda do poder de captar recursos, vemos uma atenuação do poder oligárquico, o que faz com que também as universidades 
federais fiquem desprotegidas, porque não têm mais o padrinho poderoso que vai intermediar recursos junto aos ministros do Executivo. Neste caso, estamos verificando o fim de um modelo universitário que eu chamaria de federal-oligárquico. Este modelo está esgotado e as universidades precisam reinventar, urgentemente, seu papel de Estado. É preciso que elas redescubram que, enquanto universidades, são ligadas ao Estado e não ao Executivo. Estado compreendendo: Executivo, Judiciário e o Legislativo. É necessário que o diálogo $e$ a ação, junto ao poder Legislativo e ao Judiciário, sejam muito mais ampliados e planificados do que tem sido feito até agora. Até agora o Poder Legislativo está sendo chamado para mediar crises $e$ isso me parece muito pobre em termos de relacionamento dos campi com os poderes de Estado. É necessário que a atividade seja cotidiana. Há 15 anos eu venho propondo que as entidades que congregam os administradores da universidade não se limitem a contatos tipo lobby no Parlamento Nacional, mas que estabeleçam sobretudo uma parceria constante também com o Poder Judiciário. Não raro as nossas universidades não têm dimensão do poder legal. Elas estão de tal modo presas ao Executivo e a sua arrogância que esquecem que existe um ordenamento jurídico para o país. O trato com o poder Judiciário é o menor possível, o que faz com que quase sempre o relacionamento das reitorias com o Poder Judiciário seja num momento em que o professor ou um funcionário entra com um processo na justiça contra a universidade. Mas esse também é um relacionamento muito pobre. Está na hora de a universidade refazer seu trato comunitário, isto é, que ela pense sua inserção na sociedade, e que amplie sua dimensão de Estado, diminuindo o peso do Executivo em suas considerações. Até hoje, supostamente, o caminho mais fácil qual é? faltam verbas ao reitor, ele pede uma audiência com o ministro da Educação, faz um lobby, toma chá de cadeira, até que consegue um pouco de verba. Ora, é preciso que esta seja uma das estratégias, mas não a estratégia de um reitor. É preciso que ele saiba dialogar, explicar, por exemplo, para os representantes do povo, o que significa o programa dessa universidade, que tipo de projetos científicos têm interesse político para a sociedade. Então é necessário que ele saiba expor o que está ocorrendo dentro da universidade, a importância das pesquisas que são feitas lá não apenas para o ministro, mas para os deputados, senadores, vereadores... que haja um diálogo nessa linha.

Outra coisa muito complicada: a universidade se desliga da sociedade até o momento em que irrompe uma greve. O movimento docente, por exemplo, é mestre em fazer isso. Surge uma greve e aí vamos para praça pública dar aulas para explicar à população o que é uma aula de Biologia. Isso é complicado, porque deveria ser assim no cotidiano. É preciso inventar estratégias... E uma que parece das mais importantes é a preocupação das universidades com o ensino público fundamental e médio. Atualmente não há uma política coletiva da universidade em relação a isso. Existem alguns programas, mas não assumidos pelas direções das universidades como obra coletiva. Se a sociedade acompanhasse um pouco mais o cotidiano das universidades, inclusive se beneficiando dos resultados das pesquisas, ela defenderia essa universidade com muito mais força e seria mais difícil para inimigos da universidade retirarem dela os recursos. 
Veja, nós temos a Fapesp, uma Fundação profundamente respeitada. Mas boa parte dos projetos ali financiados permanece nas gavetas; a sociedade não sabe o que eles significam, por que foram feitos etc... Uma política de divulgação e de apropriação desse conhecimento por parte das coletividades precisa ser feita. Uma abertura, e não apenas em termos de publicação dos trabalhos. Acho inconcebível que uma Fundação de Pesquisa pague por três, quatro anos para que se faça uma tese de doutorado e esse trabalho não seja publicado, fique na gaveta e no currículo do pesquisador individual - sobretudo se são pesquisas que abarcam problemas de ordem ideológica, social, de saúde... Nós temos um enorme tesouro acumulado de conhecimentos - sobretudo no centro-sul - que nos equipara a grandes centros de produção de conhecimento, mas estamos paralisados pela impossibilidade de comunicar isso à sociedade pelo ensino ou pela própria fraqueza de exposição, comunicação mesmo. Não há um canal para isso, e semelhante tarefa não pode ser obra de grupos. Tem que ser uma invenção coletiva. Se a universidade coletivamente não se dedicar a ser o motor dessa invenção, não haverá solução. Eu não acredito em nenhuma direção de universidade iluminada, em nenhuma direção da Fapesp iluminada, nem de nenhum ministério iluminado, porque não existe isso. $\mathrm{O}$ processo de comunicação do conhecimento é tão ou mais complexo que o processo de invenção do conhecimento. E como se tem uma comunidade com um padrão internacional do nível da Áustria, da Itália, num país que ainda tem analfabetos ou que tem analfabetos tecnológicos...

\section{caminhos...}

Modificar isso é um desafio para a universidade coletivamente, não é para grupos. É um problema dificílimo. Como vamos enfrentá-lo? Não sei. Sei que temos que pensar, decidir e assumir compromisso: ou com a população brasileira ou conosco mesmos e se este último for nosso compromisso, a primeira coisa que nós devemos é devolver todas as verbas que a população brasileira paga por nós.

\section{sobre a avaliação universitária}

É um atentado à produção do conhecimento. A avaliação universitária foi muito incentivada e deturpada, sobretudo após o advento do programa neoliberal, propagado pelo governo da sra. Margareth Tatcher, que tinha como função domar centros quase milenares de produção do conhecimento (Cambridge e Oxford). Por procedimentos de ordem econômica inventou-se a avaliação da produtividade, padrões de mercado. Então, nessas universidades que tinham enorme latitude de pesquisas e, ponderemos, poderiam até mesmo estar abusando de recursos de forma anti-social, o remédio veio para matar o doente. Você mediu o saber com régua curta, o saber não é um fato de mercado, mas um fato social e histórico, tem 
complexidade muito maior que a lucratividade ou a produtividade, e nele o tempo é de medida imanente. Explico o termo "medida imanente". Se você tem um tempo exterior ao tempo da própria pesquisa, você a deturpa. Uma pesquisa na Biologia, por exemplo, precisa passar pela busca das deteminações trazidas pelo material, o vivente. Um bom biólogo deve ter o tempo e o lazer suficientes para verificar como um tecido funciona e você não vai dizer como ele "deve funcionar". É preciso que o pesquisador tenha toda a latitude para verificar as possibilidades múltiplas do organismo vivo. E se você apressa o seu processo de pesquisa tendo em vista o tempo burocrático que foi dado pela Capes, você mutila o objeto da pesquisa. Pesquisa é procura e você não pode definir a priori os problemas da procura. Ela pode esgotar-se em tempo rápido, demorar um tempo médio ou definir-se em tempo longo. Uma universidade e uma comunidade científica dignas desse nome suportam o tempo rápido, o médio e o longo. No processo de avaliação é preciso discriminar, saber com qual tempo você está trabalhando. Se alguém propõe uma tese que pode ser resolvida em tempo rápido, que se cobre dele um tempo rápido. Se coloca uma complexidade maior, um tempo médio. Se uma complexidade muito maior, um tempo mais longo. Isto é: os processos de pesquisa têm de supor o direito de errar. Se você não tem direito de errar você não tem Ciência. Sempre que você tem um processo de infalibilidade de resultados ou de pressupostos você tem uma seita religiosa, política ou ideológica. É o nazismo, que tinha receitas a serem estabelecidas pelos seus cientistas. Fora disso, numa pesquisa real e numa sociedade democrática você tem que pensar de forma imanente; quer dizer: qual é o tempo suficiente para se fazer uma tese de Biologia? Certamente será diferente do da Física, ou da Matemática ou da Química e mais ainda das Ciências mais complexas, como as chamadas Ciências Humanas. Quando se estabelece um padrão único está-se ferindo a todos os padrões internos das áreas. A medida tem que ser interna, imanente, adequada ao objeto pesquisado, ao método consagrado ou em superação, porque tem isso também, você não tem sempre métodos que são aplicados. No momento em que você vê um objeto diferente você precisa engendrar um outro método; e no momento em que modifica o método você modifica a própria percepção do objeto. A avaliação que não leva em conta isso é inepta. Eu posso dizer aí um dado pessoal. Eu fiz parte da comissão de avaliação da Unicamp durante quatro anos. Nesse tempo trazia para a minha casa processos que incluíam artigos publicados, livros publicados... eu lia capítulos desses livros, procurava me inteirar, de forma imanente, da pesquisa da pessoa a quem eu estava avaliando. Agora fui informado que é proibido anexar nos relatórios a produção - o material publicado. Então eu me pergunto: sobre o que se está trabalhando? A quantidade de artigos publicados? Eu não sou contra a quantidade. Julgo que ela é um dos fatores a serem ponderados. Uma pessoa que recebe recursos públicos para fazer pesquisa e não publica nenhum artigo em vinte anos é um problema sério, que deve ser identificado. Agora, se ele publicou cento e cinqüenta artigos em cinco anos também é algo que deve ser investigado, porque é muito improvável que uma pesquisa profunda se faça de modo tão célere. A avaliação deve acompanhar, necessariamente, a

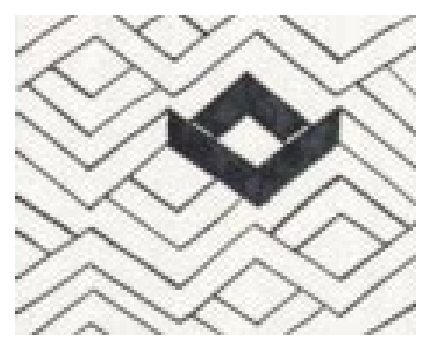


produção e a complexidade do campo epistêmico, senão é inepta. Como alguém que foi biólogo há vinte anos e nunca mais se dedicou ao trabalho produtivo na área de Biologia pode avaliar um trabalho de agora? O que nos resta? Nós que somos um elo importante na cadeia de produção de conhecimentos detemos um certo poder. Não absoluto, mas um poder relativo. Nossa atitude deve ser de atacar. Nós temos que denunciar fortemente esses mecanismos não imanentes, exteriores ao processo de conhecimento científico, e dizer que as pessoas que nos submetem a esses procedimentos extra-científicos não são cientistas. São burocratas a serviço de determinadas idéias e práticas políticas. A partir do momento em que se diz que uma tese de mestrado tem que ser feita em dois ou três anos, aceitar essa regra já significa colaborar para destruir a ciência. Houve um período, que foi de muita astúcia dos instauradores desse tipo de avaliação extra-científica, em que se desvinculou a representação da comunidade científica, sobretudo em níveis de pós-graduação, dos departamentos e da parte cotidiana dos laboratórios e dos setores da universidade. Foi quando o Governo Federal privilegiou seu relacionamento com as associações de Pós-Graduação, que diziam representar a comunidade científica. Então, uma série de medidas de ordem econômica, como a redução no tempo para as teses, foram aceitas por essas associações, que tinham um poder muito grande de barganha. Quando o Poder Federal (Capes, CNPq) não precisou mais dessas associações, instaurou seu procedimento e as colocou para fora dos processos avaliadores. Quer dizer que houve um equívoco grave por parte da comunidade acadêmica no seu todo: desvinculou-se o processo cotidiano da pesquisa e da docência do processo de representação e essas associações, que no início representavam a comunidade acadêmica, deixaram de representá-la. Passaram a representar seres em luta pela sua direção. Este equívoco é grave e, infelizmente, não podemos culpar o governo por ele; foi um equívoco da comunidade acadêmica. Quando se imaginava que ser membro de uma direção, de uma associação nacional de Pós-Graduação dava assento no $\mathrm{CNPq}$, na Capes etc...foram aceitas a desvinculação do pesquisador de base e essas direções, estabeleceu-se uma quebra dentro das universidades, que favoreceu o jogo dos que defendem a privatização. Quando hoje integrantes dessas associações reclamam do fato de a "comunidade científica", acadêmica, não estar mais sendo ouvida pelos ministérios, esquecem que eles deixaram de ouvir as bases. Um caso é a Sociedade Brasileira de Pesquisa Científica, a SBPC. No início das SBPCs você tinha uma representação que vinha da base: eram os departamentos, os laboratórios, os institutos que indicavam os integrantes da reunião e os trabalhos. A partir de certo momento, nessa lógica (exatamente a mesma seguida pela Capes e pelo (NPq), a SBPC passou a só aceitar trabalhos vindos de Associações Nacionais de Pós-Graduação, de laboratórios reconhecidos etc... a comunidade científica desdobrou-se. Nós tínhamos duas comunidades científicas: a do pesquisador de base e a dos dirigentes políticos que dirigiam as Associações de Pós-graduação ou Associações simplesmente. É claro que se ocorre esse tipo de delegação, se não existir cobrança da base, as instituições que não a respeitam, a base se reduz à insignificância. Foi o que aconteceu e a comunidade perdeu muito. Entidades como a SBPC começaram a perceber e a corrigir esse desvio. Hoje, por exemplo, já se pode apresentar um trabalho que não saia diretamente da Associação Nacional de Pós-Graduação disso ou 
daquilo, mas houve perda substancial nesse período. No caso das Humanidades, Associação Nacional de Pós-Graduação em Educação, Anped, Associação Nacional de Pós-Graduação em Ciências Sociais, Anpocs, Associação Nacional de Profissionais de Ciências Sociais, Anpof, foram as grandes monopolizadoras da comunicação e da intermediação de recursos e políticas para a Pós-Graduação no seu todo $e$ acho que elas vão ter que responder por muitos erros ocorridos neste processo.

\section{sobre o compromisso ético da universidade}

O compromisso ético da universidade (digo ético porque é coletivo, não é moral, é um compromisso social) é com a população dentro da qual ela se insere. Não tem sentido uma universidade "para si". Uma universidade sempre é relacional. Sempre é um serviço ao social. Você pode pesquisar o mais livremente possível - não existe nenhuma pesquisa, por mais especulativa que seja, por mais que seja de ponta em termos tecnológicos, que não possa se traduzir em informações para o social. Quando digo informação, penso o seguinte: temos o homem, ser social, imerso na natureza, natureza que the oferece oportunidades e riscos. Qualquer ato coletivo que seja feito no sentido de diminuir os riscos da vida humana dentro da natureza é positivo do ponto de vista ético. Todos os que aumentam o risco desta existência são negativos. A natureza e o espírito não se contradizem nessa perspectiva. Quando se tem uma série de procedimentos que dificultam ou tornam a existência do homem perigosa, enfrentamos um alarme do ponto de vista ético. Assim, de consenso, por exemplo, o protocolo de Kyoto. Para nós, seres pensantes, é uma condição básica da existência da humanidade no planeta Terra, portanto, eticamente defensável. Não que todos os itens do protocolo sejam defensáveis, mas os princípios que levaram à reunião de Kyoto o são, o que torna condenáveis todos os que, como o governo dos Estados Unidos, se recusam a aceitar essas medidas. Do ponto de vista da Ecologia, temos um terreno enorme, quase que infindável, de investigação e de verificação do que é ou não eticamente recomendável para a humanidade. Mas, seguir esse procedimento exige mais disciplina do que se costuma dizer. É fácil proclamar princípios, difícil é modificar efetivamente a vida. Por exemplo, muitas universidades que têm uma concepção altamente elogiosa de si não tem cuidados ecológicos mínimos. Muitos lagos situados em campus universitários estão poluídos pelas próprias faculdades. Experimentos em animais é outro problema seriíssimo que precisa ser investigado. Por enquanto estamos apenas no nível do protesto humanitário, ou da justificativa puramente sensível, mas há toda uma zona intermediária que deve ser pensada. Como diz Levi Strauss: se agimos de forma inumana com os animais é porque já demos o passo de agir de forma inumana com o ser humano. Então, não é um problema apenas de bondade, caridade, piedade ou alma fraca, que não pode suportar a dor dos outros. Trata-se de uma definição de o que você quer para o ser humano e para você mesmo. São problemas extremamente complexos, mas de enunciação simples. O passo deste enunciado que eu faço quase como que uma espécie de 
refrão: "aquilo que possibilita aumentar as oportunidades de sobrevivência, de ampliação do tempo do ser humano individual e coletivo na Terra é eticamente recomendável. Aquilo que apressa o fim é negativo". O que expande o ser humano, a vida, os valores, a consciência, o espírito, em última instância (música, poesia etc...), deve ser incentivado e cultivado. $\mathrm{O}$ que retrai, traz ódio, tristeza, isolamento, deve ser evitado e administrado. Não podemos decretar o fim da dor ou da maldade humana. Mas podemos administrar. Administrar é uma arte, muito difícil, mas tem que ser feita. A ética ajuda, traz elementos para esta reflexão. Mas não traz soluções.

Engana-se profundamente quem acha que estudando a Ética vai encontrar soluções. Aliás, isso é antiético. Quem propõe soluções éticas sem estudar toda a complexidade do relacionamento entre homem e natureza, homem e homem exerce ilegitimamente a tarefa de pensar. Sou refratário, por exemplo, a dizer qual "o papel" da universidade. Para isso é preciso sair da universidade e da sociedade e, de um ponto de vista divino, verificar todo o contexto para dizer: "este é o papel!". Nós somos atores e cabe-nos tentar reinventar nossa fala, não decretar o que ela deve ser; dar respostas provisórias, sempre provisórias, e capazes de ser corrigidas, ampliadas e superadas pelo nosso próximo. Este exercício da morte da individualidade é muito sério. Não existe processo de humanização sem expansão da individualidade. Mas essa expansão tem que passar pelo processo da sua morte. Ela precisa se negar. Se você sempre está expandindo seu próprio ponto de vista, sua própria consciência, chega um ponto em que você está destruindo outras. Na experiência democrática é necessário que você cale um pouco o seu desejo de expansão e permita que o outro se expanda um pouco, para que haja troca. Eu gosto muito das imagens utilizadas por Leroi-Gourhan, um grande etnólogo. Ele diz que, no processo da cultura, $e$ no processo da cultura tecnológica sobretudo, são possíveis duas imagens que podem definir o que o processo tecnológico e científico não podem ser. Não podem ser, por exemplo, descritos pela imagem da ameba, que é a permanente repetição do mesmo. A outra imagem que não pode ser usada para descrever a invenção técnica ou de conceitos é a do som: um som é sempre diferente do outro, é permanente diferença. Ora, a música se faz com o mesmo e com o diferente. A música me parece uma imagem mais próxima de o que deve ser a cultura humana do que a figura puramente biológica da ameba ou tecnológica do som. Para trabalhar a cultura são necessários o mesmo e o outro, caso contrário não há invenção, nem comunicação. É fácil proclamar o diálogo. Mas fazer com que o outro exista significa matar um pouco de nós e ninguém gosta de fazer esse harakiri doloroso. Mas é esta dor que faz com que existam culturas refinadas. A disciplina, o trabalho, a escuta alheia, a correção do erro... tudo isso faz com que brote a diferença e obriga a perceber de modo crítico o diferente. Isso se chama Ciência, saber, que define um caminho difícil. Gosto muito do aforismo latino posto por Spinoza no final de sua Ética: "tudo o que é belo, é difícil e raro".

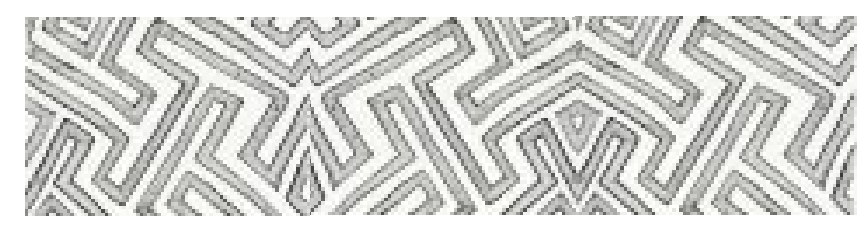

